\title{
Space Weather Nowcasting of Atmospheric Ionizing Radiation for Aviation Safety
}

\author{
Christopher J. Mertens ${ }^{1}$, John W. Wilson ${ }^{1}$, Steve R. Blattnig ${ }^{1}$, Stan C. Solomon ${ }^{2}$, Michael \\ J. Wiltberger ${ }^{2}$, Joseph Kunches ${ }^{3}$, Brain T. Kress ${ }^{4}$, and John J. Murray ${ }^{1}$ \\ ${ }^{1}$ NASA Langley Research Center \\ Hampton, Virginia 23681 \\ ${ }^{2}$ High Altitude Observatory, National Center for Atmospheric Research \\ Boulder, Colorado 80301 \\ ${ }^{3}$ NOAA Space Environment Center \\ Boulder, Colorado 80305-3337 \\ ${ }^{4}$ Dartmouth College \\ Hanover, New Hampshire 03755
}

\begin{abstract}
There is a growing concern for the health and safety of commercial aircrew and passengers due to their exposure to ionizing radiation with high linear energy transfer (LET), particularly at high latitudes. The International Commission of Radiobiological Protection (ICRP), the EPA, and the FAA consider the crews of commercial aircraft as radiation workers. During solar energetic particle (SEP) events, radiation exposure can exceed annual limits, and the number of serious health effects is expected to be quite high if precautions are not taken. There is a need for a capability to monitor the real-time, global background radiations levels, from galactic cosmic rays (GCR), at commercial airline altitudes and to provide analytical input for airline operations decisions for altering flight paths and altitudes for the mitigation and reduction of radiation exposure levels during a SEP event. The Nowcast of Atmospheric Ionizing Radiation for Aviation Safety (NAIRAS) model is new initiative to provide a global, real-time radiation dosimetry package for archiving and assessing the biologically harmful radiation exposure levels at commercial airline altitudes. The NAIRAS model brings to bear the best available suite of Sun-Earth observations and models for simulating the atmospheric ionizing radiation environment. Observations are utilized from ground (neutron monitors), from the atmosphere (the METO analysis), and from space (NASA/ACE and NOAA/GOES). Atmospheric observations provide the overhead shielding information and the groundand space-based observations provide boundary conditions on the GCR and SEP energy flux distributions for transport and dosimetry simulations. Dose rates are calculated using the parametric AIR (Atmospheric Ionizing Radiation) model and the physics-based HZETRN (High Charge and Energy Transport) code. Empirical models of the near-Earth radiation environment (GCR/SEP energy flux distributions and geomagnetic cut-off rigidity) are benchmarked against the physics-based CMIT (Coupled MagnetosphereIonosphere-Thermosphere) and SEP-trajectory models.
\end{abstract}

\subsection{Introduction}




\subsection{Scientific Background}

Atmospheric ionizing radiation is of interest to air transportation safety assessment because it's the primary source of human exposure to radiations with high linear energy transfer (LET). High-LET radiation is effective at producing chemically active radicals in biological tissues that alter the cell function or result in cell death. Consequently, there is increased concern for potential health outcomes among passengers and crew in commercial aviation [Wilson et al., 2003]. Atmospheric ionizing radiation is produced by extraterrestrial radiations incident on the Earth's atmosphere. There are two sources of the extraterrestrial radiations: the ever-present, background galactic cosmic rays (GCR), with origins outside the solar system, and transient solar energetic particles (SEP) associated with solar storm activity lasting several hours to days with widely varying intensity.

GCR consist of roughly 90\% protons and $8 \%$ helium nuclei with the remainder being heavier nuclei and electrons [Gaisser, 1990]. When these particles penetrate the magnetic fields of the solar system and the Earth and reach the Earth's atmosphere, they collide with air molecules and create cascades of secondary radiations of every kind [Reitz, 1993]. The collisions are primarily due to Coulomb interactions of the GCR particle with orbital electrons of the air molecules, delivering small amounts of energy to the orbital electrons and leaving behind electron-ion pairs [Wilson et al., 1991]. The ejected electrons usually have sufficient energy to undergo similar ionizing events. The cosmic ions lose a small fraction of their energy and must suffer many collisions before slowing down. On rare occasions the cosmic ion will collide with the nucleus of an air atom in which large energies are exchanged and the ion and nucleus are dramatically changed by the violence of the event. The remnant nucleus is highly disfigured and unstable, emitting further air nuclear constituents and decaying through the usual radioactivity channels [Wilson et al., 1991]. The most important secondary particle created in GCR-air interactions is the neutron. Because of its charge neutrality, the neutron penetrates deep into the atmosphere, causing further ionization events along its path and contributing over half the atmospheric radiation exposure [Wilson et al., 1993]. Furthermore, neutron exposures pose a relatively high health risk, since the massive low-energy ions resulting from neutron interactions always produce copious ions in the struck cell and repair is less efficient for these events [Wilson et al., 2000].

The intensity of the atmospheric radiations, composed of GCR primary and secondary particles, their energy distribution, and their effects on aircraft occupants vary with altitude, location in the geomagnetic field, and the time in the sun's magnetic activity (solar) cycle [Reitz, 1993; Wilson, 2000; and Heinrich et al., 1999]. The atmosphere provides shielding, which depends on the overhead atmospheric depth. The geomagnetic field provides a different kind of shielding, by deflecting low-momentum charged particles back to space. Because of the orientation of the geomagnetic field, which is predominately dipolar in nature, the polar regions are susceptible to penetrating GCR (and SEP) particles. At each geographic location, the minimum momentum per unit charge (magnetic rigidity) a vertically incident particle can have and still reach a given 
location above the earth is called the geomagnetic vertical cutoff rigidity. The local flux of incident GCR at a given time varies widely with geomagnetic location and the solar modulation level. When solar activity is high, GCR flux is low, and vice versa. The dynamical balance between outward convective flux of solar wind and the inward diffusive flux of GCR is responsible for the anti-correlation between the incident GCR and the level of solar activity [Clem et al.; 1996; Parker, 1965].

It is now generally understood that SEP events arise from coronal mass ejections (CME) from active regions of the solar surface [Kahler, 2001; Wilson et al., 2004]. The CME propagates through interplanetary space carrying along with it the local surface magnetic field frozen into the ejected mass. There is a transition (shock) region between the normal sectored magnetic structure of interplanetary space and the fields frozen into the ejected mass, which forms a transition region (shock) where the interplanetary gas is accelerated forming the SEP. As the accelerated region passes an observation point, the flux intensity is observed to increase dramatically, and no upper limit in intensity is known within the shock region. The SEP energy spectrum obtained in the acceleration process is related to the plasma density and CME velocity. During a solar storm CME event, the number flux and energy flux distributions incident at Earth's atmosphere are a combination of the GCR and SEP distributions. The SPE-air interaction mechanisms are the same as GCRair interactions described above. The atmospheric radiations caused by a SEP also vary with altitude and geomagnetic field.

\subsection{Identification of Management/Policy Issues and End-User Community}

GCR radiations that penetrate the atmosphere and reach the ground are low intensity. However, the intensities are more than two orders of magnitude greater at commercial aircraft altitudes. At the higher altitudes of High Speed Civil Transport (HSCT), the GCR intensity is another two orders of magnitude higher [Wilson et al., 2003]. When the possibility of high-altitude supersonic commercial aviation was first seriously proposed (The Supersonic Transport program proposed in 1961), Foelsche brought to light a number of concerns about associated atmospheric radiation exposure due to GCR and SEP, including the secondary radiations [Foelsche, 1961; Foelsche and Graul, 1962]. Subsequently, Foelsche et al. [1974] conducted a detailed study of atmospheric ionizing radiation at high altitudes from 1965 to 1971 at the NASA Langley Research Center (LaRC). The study included a comprehensive flight program in addition to theoretical investigations. The measured data and theoretical calculations were integrated into a parametric Atmospheric Ionizing Radiation (AIR) model [Wilson et al., 1991]. Prior to that study the role of atmospheric neutrons in radiation exposure was generally regarded as negligible [Upton et al., 1966]. The LaRC studies revealed neutron radiation to be a major contributor to aircraft GCR exposure. Still the exposure levels were comfortably below allowable exposure limits for the block hours typical of airline crews of that time, except during a possible SEP event (less than 500 block hours were typical of the 1960's, although regulation allowed up to 1000 hours).

There have been a number of significant changes since the original work of Foelsche [Wilson, 2002]. A partial list of these changes, relevant to the development of the 
NAIRAS model, are: (1) the highly ionizing components of atmospheric radiations are found to be more biologically damaging than previously assumed and the associated relative biological effectiveness for fatal cancer has been increased [ICRU 1986; ICRP 1991]; (2) recent studies on developmental injury in mice embryos indicate large relative biological effectiveness for protection in prenatal exposures [Jiang et al., 1994]; (3) recent epidemiological studies (especially the data on solid tumors) and more recent atom-bomb survivor dosimetry have resulted in higher radiation risk coefficients for gamma rays [UNSCEAR 1988; NAS/NRC 1980; ICRP 1991], resulting in lower proposed permissible limits [ICRP 1991; NCRP 1993]; (4) subsequent to deregulation of the airline industry, flight crews are logging greatly increased hours [Bramlitt, 1985; Wilson and Townsend, 1988; Friedberg et al., 1989; Barish, 1990]; and (5) airline crew members are now classified as radiation workers [McMeekin, 1990; ICRP 1991].

The last point (i.e., (5)) is particularly illuminating. The International Commission on Radiological Protection (ICRP), as well as the EPA and FAA, consider the crews of commercial aircraft as radiation workers [Wilson et al., 2003]. The FAA estimates annual subsonic aircrew exposures to range from 0.2 to $9.1 \mathrm{mSv}$ compared to $0.5 \mathrm{mSv}$ exposure of the average nuclear power plant worker. Aircrews may receive exposures above recently recommended allowable limits for even radiation workers when flying the maximum allowable number of flight hours. Although as a group the health risks of aircrew are low, Band [1990] found increased risks of several types of cancer among Canadian commercial pilots. There is further concern for prenatal injury in high altitude flight, as the US National Institute for Occupational Safety and Health continues to study early pregnancy outcomes among commercial flight attendants [Grajewski et al., 1994; Whelan, 2002]. Frequent-flyer business passengers are likely exposed to even higher doses than aircrew, since flight hours are not restricted for airline passengers. In addition, if a large SEP occurs during flight, both passengers and crew may greatly exceed allowable limits and potentially serious health outcomes are possible [Barish, 2004].

There are currently no data or models that can effectively map the atmospheric radiation field on a continuous basis in order to track and regulate radiation exposure and associated health risks to aircrew and passengers on commercial flights.

\subsection{Model Objectives, Benefits, and Relevance}

Recognizing the potential impact on present day passenger and crew exposures, due to the changes since the original work of Foelsche, as described above, further studies were started at LaRC. The resulting flight package was a collaboration of fourteen institutions in five countries and consisted of eighteen instruments. New measurements [Wilson et al., 2003] were made and new advances in theoretical modeling [Clem et al., 1996], which culminated in the AIR workshop [Wilson et al., 2003].

Following the recent LaRC-sponsored AIR workshop, a number of recommendations for future work were put forth [Wilson et al., 2003]. The recommendations relevant to the NAIRAS model development are: (1) utilize satellite input data to provide real-time mapping of GCR and SEP radiation levels to provide guidance in exposure avoidance; 
and (2) utilize state-of-the-art transport codes and nuclear databases to generate input data to the AIR model. The need to combine satellite observations of the meteorological fields and the space environment variables with HZE (high charge and energy) particle transport codes was further highlighted in a recent Airline Space Weather Workshop [Friedberg, 2004]. The objective of the NAIRAS model is to address these two recommendations, but significantly go beyond recommendation (2) by using physicsbased, state-of-the-art transport code directly in simulating the atmospheric radiation exposure levels.

NAIRAS is a new initiative to develop a prototype, global, Nowcast of Atmospheric Ionizing Radiation for Aviation Safety (NAIRAS) model for calculating dose equivalent rates at commercial airline altitudes. The NAIRAS results will provide a continuous assessment of the atmospheric ionizing radiation field needed for the commercial airlines to track individual aircrew radiation exposures levels, in order that the airlines and the FAA can develop policy and procedures for radiation exposure limits and exposure mitigation to aircrew. During SEP events, NAIRAS will provide timely data output necessary for airline management to make critical decisions that balance cost to flight path alterations against radiation exposure and health risks to passenger and crew.

The most significant and innovative features of the NAIRAS model are: (1) the atmospheric transport is simulated using HZETRN (High Charge and Energy Transport), a state-of-the-art, physics-based HZE+neutron+meson+muon transport code, which is (2) driven by real-time measurements of the solar-terrestrial environment - i.e., meteorological data of atmospheric density, observation-based models of GCR/SEP differential number flux spectrum (DNFS), and observation-based models of geomagnetic cutoff rigidity. Currently NOAA/SEC maintains a web site with space weather forecast products for the aviation community. The products include measurements of several space radiation environment parameters and a forecast on the likelihood and the expected level of space weather activity. The NOAA aviation products do not include the radiation fields that effect human health. The FAA's Civil Aerospace Medical Institute provides a web interface to the CARI-6 program. CARI-6 calculates effective dose rates of the GCR radiations for user-defined flight paths. The FAA web site does not maintain a real-time, global database.

There are no existing data or models that provide a comprehensive (i.e., comprehensive in terms of input observation data included and comprehensive in terms of the transport physics included in the real-time calculations), global, real-time assessment of the radiation fields that affect human health and safety. Thus, the NAIRAS model concept provides an atmospheric radiation exposure assessment that significantly extends current capabilities.

\subsection{Description of the Parametric AIR Model}

The original LaRC study (1965 to 1971) commissioned over 300 flights over most of the duration of solar cycle 20 on high-altitude aircraft and balloons to study both the background radiation levels over the solar cycle and to make measurements during SEP 
events. The LaRC flight package consisted of a 1-10 MeV neutron spectrometer, tissue equivalent ion chamber, and nuclear emulsion for nuclear reaction rates in tissue. Monte Carlo calculations [Wilson et al., 1970; Lambiotte et al., 1971] for incident GCR protons were used to extend the neutron spectrum to high energies. The measured data was combined with the theoretical calculations and integrated into a parametric Atmospheric Ionizing Radiation (AIR) model, parameterized by neutron monitor count rate, geomagnetic vertical cutoff rigidity, and atmospheric depth. Solar cycle modulation of the GCR spectrum is parameterized by the ground-level neutron monitor count rates. Geomagnetic momentum shielding and overhead atmospheric shielding are parameterized by the vertical geomagnetic cutoff rigidity and atmospheric depth, respectively. The neutron flux $\left(\mathrm{cm}^{-2} \mathrm{sec}^{-1}\right)$ component to the atmospheric radiations is converted to dose equivalent and total dose using $3.14 \mu \mathrm{Sv} \mathrm{cm}{ }^{2}$ sec $\mathrm{hr}^{-1}$ and $0.5 \mu \mathrm{Gy} \mathrm{cm}{ }^{2}$ sec $\mathrm{hr}^{-1}$, respectively. The charged particle component to the atmospheric radiations is obtained from data taken by Neher [1961, 1967, 1971] and Neher and Anderson [1962] as compiled S. B. Curtis (Boeing 1969) and utilized by Wallace and Sondhaus [1978]. The charge particle atmospheric ionization rates are directly converted to dose equivalent and total dose using measurement data from the tissue equivalent ion chamber. Nuclear stars in tissue are estimated from the nuclear emulsion measurement data after subtraction of the neutron-induced stars [Wilson et al., 1991].

Considerable progress was made in the recent LaRC study [Wilson et al., 2005a, 2003a]. In particular, improvements were made in the high-energy neutron spectrum from a combination of flight measurements and new theoretical calculations using the FLUKA transport code [Clem et al., 2003]. Furthermore, an improved model was developed for geomagnetic cutoff rigidity applicable for years 1945 to 2020 which can also incorporate geomagnetic storm effects [De Angelis et al., 2003].

Figure 1 shows altitude profiles of neutron flux and ionization rates computed from the AIR model for summer and winter atmospheric conditions at various latitudes in the northern hemisphere, for both solar maximum and solar minimum conditions. Figure 2 shows the corresponding profiles of dose equivalent rates. The two most noticeable features are: (1) the significant increase in flux, ionization rates, and dose-equivalent rates at high-latitudes, and (2) the peak in these quantities occur near the typical cruising altitudes of commercial aircraft flying international routes $(\sim 10-12 \mathrm{~km})$. The low altitude results are less reliable because of the limited altitude range of the balloon and flight measurements used to develop the AIR parameterization.

Figures 1 and 2 show the dose-equivalent rates for summer and winter northern hemispheres at $12 \mathrm{~km}$ for both solar minimum and solar maximum conditions, respectively. The North Atlantic flight corridor is one of the busiest in the world and it is among the most highly exposed routes in airline operations. Flights over Canada are among the most highly exposed. Much of European flight is subject to somewhat lower exposure levels. From Table 1 it is clear that aircrew flying the Northern Atlantic or Canadian routes can exceed allowable annual exposure levels $(10 \mathrm{mSv}$, see footnote $\mathrm{b}$ in Table 1) in a 1000-hour block at solar minimum. For solar maximum condition, aircrew can reach $60 \%$ to $70 \%$ of the annual recommend allowance in a 1000 -hour block. The 
occurrence of a SEP could increase radiation exposure well over recommended and allowable levels.

The AIR model will be used as an intermediate tool to develop the interface between real-time neutron monitor data, the atmospheric depth data, and the observation-based geomagnetic cutoff model. This will allow simultaneous development of the integration of the components of the HZETRN code and the interface between HZETRN and the data-driven GCR/SEP models. Once the geomagnetic cutoff model and the atmospheric depth data has been validated, verified, and benchmarked using the AIR model, these models and data input will be to integrated into HZETRN. A common I/O interface and data definitions will make this step effortless. Thus, HZETRN will replace the AIR model for dose rate calculations, since the physics-based HZETRN is the best alternative. The purpose of the AIR model is to facilitate the integration, testing, and benchmarking of the components of the NAIRAS model.

\subsection{Description of the NAIRAS Model Components}

\subsection{Transport Code}

The LaRC HZETRN transport code has a long and successful history for rapidly and accurately modeling the particle radiation fields in the space environment. The LaRC code is used to calculate dosimetry parameters on the International Space Station (ISS) and assess astronaut risk to space radiations, including spacecraft and human geometry for final exposure evaluation. It is used to develop design tools for materials research for radiation shielding protection, to calculate HZE propagation through Earth's atmosphere, and to evaluate radiation exposures for epidemiological studies [Wilson et al., 1997, 2003, and references therein].

The relevant transport equations are the linear Boltzmann equations derived on the basis of conservation principles [Wilson et al., 1991]. The transport equation for the flux density $\phi_{j}(x, \Omega, E)$ for particle type $j$ is given by

$$
\mathbf{\Omega} \bullet \nabla \phi_{j}(\mathbf{x}, \boldsymbol{\Omega}, E)=\sum_{k} \int \sigma_{j k}\left(\boldsymbol{\Omega}, \boldsymbol{\Omega}^{\prime}, E, E^{\prime}\right) \phi_{k}\left(\mathbf{x}, \boldsymbol{\Omega}^{\prime}, E^{\prime}\right)-\sigma_{j}(\boldsymbol{\Omega}, E) \phi_{j}(\mathbf{x}, \boldsymbol{\Omega}, E)
$$

where $\sigma_{j}(E)$ and $\sigma_{j k}\left(\Omega, \Omega^{\prime}, E, E^{\prime}\right)$ are the target medium macroscopic cross sections. The $\sigma_{j} k\left(\Omega, \Omega^{\prime}, E, E^{\prime}\right)$ represent all those processes by which type $k$ particles moving in direction $\boldsymbol{\Omega}^{\prime}$ with energy $E^{\prime}$ produce a type $j$ particle in direction $\boldsymbol{\Omega}$ with energy $E$ (including decay processes). The total cross section $\sigma_{j}(\Omega, E)$ with the target medium for each particle type is

$$
\sigma_{j}(\boldsymbol{\Omega}, E)=\sigma_{j, a t}(\mathbf{\Omega}, E)+\sigma_{j, e l}(\mathbf{\Omega}, E)+\sigma_{j, r}(\mathbf{\Omega}, E)
$$

The first term above refers to collisions with atomic electrons, the second term refers to elastic ion-nucleus scattering, and the third contains all relevant nuclear reactions and 
radioactive decay processes. The corresponding differential cross sections are similarly ordered.

The solution of (1) involves hundreds of multidimensional integral-differential equations, which are coupled together by thousands of cross terms and must be solved selfconsistently subject to boundary conditions ultimately related to the external environment. HZETRN determines the solution of (1) for the transport of HZE (High Charge and Energy) particles, light-ions (protons through alpha particles), neutrons, and mesons and muons. The transport of each particle type described above employs different approximations and requires different solution approaches. Details of the analytical and computational solution approaches implemented in HZETRN are given by Wilson et al. [2004b, 1997, 1991, and references therein], Clowdsley et al. [2000, 2002], and Blattnig et al. [2004, 2005].

Figures 5-8 show examples of atmospheric GCR and SEP flux and dose-equivalent rates computed by HZETRN for the solar minimum conditions and the September 1989 SEP event. Figure 5 shows the differential flux for neutrons and selected ions for solar minimum at various atmospheric depths. The neutron flux quickly builds up and even exceeds the proton flux. At depths greater than $100 \mathrm{~g} / \mathrm{cm} 2$, the heavy ion flux quickly approaches zero, leaving mostly protons, neutrons, electrons and muons. Figure 6 shows the corresponding total dose-equivalent rates at various atmospheric depths for solar minimum. The event-integrated proton and neutron flux and total dose-equivalent rates for the September 1989 SEP events are shown in Figures 7 and 8, respectively.

The next sections briefly discuss the models that specify the input data for the HZETRN transport calculations, namely, the GCR/SEP flux incident on Earth's atmosphere, the geomagnetic cutoff rigidity, and atmospheric pressure versus altitude. The results presented in Figures 5-8 assumed a zero cutoff rigidity for all incident ions.

\subsection{GCR Model}

The solutions to the Boltzmann transport equation (1) are unique in any convex region for which the inbound flux of each particle type is specified everywhere on the bounding surface [Wilson et al., 1997]. For real-time transport calculations of GCR particles, we use the Badhwar and O'Neill [1996, 1994, 1993, 1992, 1991] model to specify the incident GCR DNFS at the top of the atmosphere. The GCR DNFS is derived by solving a steady-state Fokker-Planck equation for the transport of GCR particles through the heliosphere. The local interstellar spectrum (LIS) at $100 \mathrm{AU}$ is parameterized by

$$
j_{L I S}(E)=j_{o} \beta^{\delta}\left(E+E_{o}\right)^{-\gamma} .
$$

In the above equation, $\mathrm{E}$ and $E_{0}$ are the particle's kinetic and rest energy per nucleon, respectively, and $\beta$ is the particle's velocity divided by the speed of light. The free parameters $\left(j_{0}, \delta\right.$, and $\gamma$ ) are determined by a fit to the NASA/ACE data, as described below. 
The diffusion coefficient in the Fokker-Planck transport equations are parameterized by

$$
k(r, t)=\left(k_{o} / V_{S W}\right) \beta R\left[1+\left(r / r_{o}\right)^{2}\right] / \Phi(t)
$$

where $V_{S W}$ is the solar wind velocity, $\beta$ is the particle's velocity divided by the speed of light, $\mathrm{R}$ is the particle's rigidity, radial distances from the sun in units of AU are $\mathrm{r}$ and $r_{0}$, $\Phi$ is the heliospheric potential, and $\mathrm{t}$ is time. Nominal values are specified for $k_{0}, V_{S W}$, and $r_{0}$. The single fit parameter is taken to be the heliospheric potential.

Figure 9 shows a sample output for the Badhwar and O’Neill GCR model for a select number of ions. The figure shows the LIS spectra and the spectra at solar maximum and solar minimum conditions. The proton and alpha spectra were fit to IMP-8 data. The lithium through nickel $(\mathrm{Z}=3-28)$ spectra were fit to CRIS measurements taken from NASA/ACE satellite (50-500 MeV/nucleon). The high-energy spectra (1-35 $\mathrm{GeV} /$ nucleon) were fit to $\mathrm{C} 2$ observations measured by the NASA/HEAO-3 satellite [Engelmann et al., 1999].

The recently updated version of the Badhwar and O’Neill GCR model can be driven by ground-based neutron monitor count rate measurements. A reference heliospheric potential was fit to the ACE/CRIS oxygen spectra. The free parameters in (3) were fit using the reference heliospheric potential and ACE/CRIS spectral measurements for the remaining nuclei. A simple linear scaling relationship was determined between the heliospheric potential derived from the ACE/CRIS measurements and the CLIMAX neutron monitor count rate, which enables the heliospheric potential to be calculated from 1951 to the present. Thus, the real-time modulation of the GCR DNFS by the solar wind can be captured using neutron monitor data. Real-time neutron monitor data, with geomagnetic cutoff rigidities of $2 \mathrm{GV}$ or greater, will be obtained from sites at IZMIRAN (Moscow, Russia), YAKUTSK (Russia), and LOMNICKY (Slovakia). We will derive linear scaling formulas between the real-time neutron monitor data and the heliospheric potential derived during the ACE/CRIS measurement period.

\subsection{SEP Spectrum}

SEP proton and alpha DNFS will be obtained in real-time from NOAA's Geostationary Operational Environmental Satellite (GOES) Space Environment Monitor (SEC) measurements. The Energetic Particle Sensor (EPS) and the High Energy Proton and Alpha Detector (HEPAD) sensors on GOES/SEC measure energetic differential proton and alpha flux. EPS provides seven-channel differential proton flux from 0.8 to $500 \mathrm{MeV}$ and six-channel differential alpha flux from 4 to $500 \mathrm{MeV}$ per nucleon. HEPAD extends the EPS energy ranges to greater than $700 \mathrm{MeV}$ for protons and $3400 \mathrm{MeV}$ per nucleon for alpha particles. These measurements will be used to fit a power law spectrum [Wilson et al., 2003a] for the incident proton/alpha flux such that the DNFS integrated over the spectral channel subintervals agree with the EPS and HEPAD measurements, in the leastsquare sense. 


\subsection{Geomagnetic Cutoff Rigidity}

The geomagnetic cutoff rigidity determines the minimum energy for the transport of GCR/SEP particles through the atmosphere using HZETRN. A baseline semi-empirical cutoff rigidity model is based on the worldwide grid maps produced by Shea and Smart [1983] and Smart and Shea [2000, 2001]. Vertical cutoff rigidities from Shea and Smart data are shown in Figure 10. Note the correlation between high rigidity in Figure 10 and low dose rates in Figures 3-4, and vice versa.

The baseline semi-empirical geomagnetic cutoff rigidity model will be based on lookup tables of a global grid of vertical cutoff rigidities calculated from the present to 2020. The vertical cutoff rigidities are calculated from numerical solutions of charged particle trajectories in the geomagnetic field, which is simulated using the International Geomagnetic Reference Field (IGRF) model [Barton, 1997], using the techniques advanced by Shea and Smart [1983] and Smart and Shea [2000, 2001]. The IGRF model includes dipolar and non-dipolar contributions to the geomagnetic field.

The global grid of vertical cutoff rigidities described above captures the cutoff rigidity during quiescent conditions. The simple Stormer rigidity relations [Stormer, 1930] for a dipolar field can be used to derive analytical scaling factors to adjust the tabulated vertical rigidities to allow for oblique angles of incidence of the GCR/SEP particles and the inclusion of geomagnetic storm effects [De Angelis et al., 2004; Wilson et al., 1991, 2003a,b]. Accounting for oblique angles, by defining the cone of acceptance, is particularly important for the solid angle integration in HZETRN in calculating the particle flux and dose rates.

The parameter that accounts for perturbations in the cutoff rigidities due to geomagnetic storms is a change in the horizontal component of the geomagnetic field at the magnetic equator [Kuhn et al., 1965; Wilson et al., 1991, 2003; De Angelis et al., 2004]. By applying a constant horizontal magnetic field to the particle trajectory equations describe by the Stormer theory, the vertical cutoff rigidity can be described by the following equation

$$
R=14.9 \cos ^{4} \lambda_{m}\left[1+\frac{H_{s t} R_{e}^{3}}{M}\left(\frac{4}{\cos ^{6} \lambda_{m}}-1\right)\right]
$$

where $\mathrm{R}$ is the cutoff rigidity in units of GV. In the above equation, $\lambda_{m}$ is the magnetic latitude, $R_{e}$ is the earth radius, $\mathrm{M}$ is magnetic dipole moment of the earth, and $H_{s t}$ is the horizontal component of the storm-time magnetic field perturbation. Using the Dst-index to parameterize $H_{s t}$, Figure 11 shows the effect of geomagnetic field perturbation on the cutoff rigidity for recent solar-geomagnetic storms. The overall effect is a decrease in the cutoff rigidity, particularly at mid- to high-latitudes. Thus, particles that would normally be shielded (i.e., deflected) by the geomagnetic field during quiescent conditions have full access to the atmosphere during geomagnetic storm periods. 
The semi-empirical geomagnetic cutoff model described above will be extended by driving it with real-time observations of the interplanetary magnetic field (IMF) and solar wind parameters. Real-time assessments of the change in the horizontal component of the geomagnetic field can be captured by dynamically including the effects of the ring current, which is included in the Tsyganenko [1989, 2002] T96 (and later models) empirical magnetic field model.

In summary, the baseline geomagnetic cutoff rigidity model will consist of a tabulated global database of vertical cutoff rigidities computed from the present time period to 2020 in one year increments using the techniques of Smart and Shea [2000, 2001]. Analytic scaling relations based on Stormer theory will be used to define the angle of acceptance and to include dynamical perturbations to the horizontal component of the geomagnetic field [De Angelis et al., 2004; Wilson et al., 1991, 2003a,b]. Real-time perturbations to the horizontal component of the geomagnetic field will be modeled by driving the T96 magnetic field model [Tsyganenko, 1989, 2002] with measurements of IMF and solar wind pressure from the NASA/ACE satellite and Dst-index obtained from NOAA/SEC.

A more sophisticated calculation of cutoff rigidity during magnetically disturbed periods can be provided by the use of a full numerical simulation using the coupled magnetosphere-ionosphere-thermosphere (CMIT) model [Wiltberger et al., 2004]. This model combines the Lyon-Fedder-Mobarry MHD simulation of magnetospheric dynamics [Lyon et al., 2004] with the Thermosphere-Ionosphere Nested Grid (TING) model for the upper atmosphere and ionosphere [Wang et al., 1999]. It can be run using solar wind and IMF data such as is available in near-real-time from the NASA/ACE spacecraft. The Center for Integrated Space-weather Modeling (CISM) [Luhmann et al., 2004; Spence et al., 2004] is developing a comprehensive model for studying the interaction of solar energetic particles with the magnetosphere using a 3D Lorentz integration of SEP trajectories in electric and magnetic fields taken from the CMIT model [Kress et al., 2005, 2004; Hudson et al., 2004; Weygand and Raeder, 2005]. It can be employed to obtain a detailed morphology of the cutoff rigidity using a dynamic magnetic field which results from geomagnetic activity that typically accompanies these events. We will further develop this capability in conjunction with the CMIT model and investigate its applicability to use with combined inputs from solar wind, IMF, and energetic particle data. These comprehensive physics-based geomagnetic cutoff simulations will also be used to benchmark the semi-empirical cutoff model and characterize its uncertainty. A common interface will be defined so that this comprehensive physics-based approach can be merged into the NAIRAS model as the MHD-based model matures and becomes computational feasible for real-time simulations.

\subsection{Meteorological Fields}

Both the AIR model and HZETRN are parameterized by atmospheric depth in units of

$\mathrm{g} / \mathrm{cm}^{2}$. Real-time, global atmospheric depth is determined by pressure and geopotential 
height data obtained from the Met Office (METO) three-dimensional variational data assimilation (3-D-Var) system [Lorenc et al., 2000], which is an update of the analysis method of Swinbank and O'Neill [1994]. Column abundance (or atmospheric depth in our units) is determined at each METO pressure surface by integrating atmospheric density over vertical height. Atmospheric depth $\left(\mathrm{g} / \mathrm{cm}^{2}\right)$ is obtained at the commercial airline altitudes by linearly interpolating column densities at the METO pressure surfaces linearly in log pressure, using the geopotential height data at each pressure surface. Notice that the dose rates in Figures 1-4 are greater in the northern hemisphere polar region in January compared to July because the pressure level is lower in January, reducing the atmospheric shielding effect.

\subsection{Conclusions}

The Nowcast of Atmospheric Ionizing Radiation for Aviation Safety (NAIRAS) model is an analytical tool that will provide the first-ever, global, real-time, atmospheric ionizing radiation dosimetry package for archiving and assessing radiation exposure levels at commercial airline altitudes that have potentially harmful health outcomes. The planned web interface to NAIRAS will enable the radiation exposure levels of crewmembers to be monitored on a continual basis, as individuals or as groups. Flight path coordinates can be entered to track the radiation exposure for crewmembers as individuals. A "phantom" pilot feature will enable one to quickly evaluate the accumulated exposure levels for typical flight schedules on a representative set of flight paths (e.g., New York to London, Chicago to Hong Kong, etc.). NAIRAS data will provide the FAA and the commercial airline industry with valuable information for developing policies and procedures for modifying aircrew travel schedules so crewmembers do not exceed annual or career radiation exposure limits. SEP events are particularly worrisome since annual radiation exposure limits can be exceeded in one flight, and the potential for serious health outcomes is expected to be high with prenatal exposures especially risky. NAIRAS results will provide critical data for airline management decisions regarding flight-path alterations during SEP events, which must balance the cost incurred by rerouting against mitigating the potential health risks. NAIRAS results will also provide the input data for researchers and analysts in the public health sector (e.g., NIOSH) to improve understanding of the radiobiological effects and health outcomes of atmospheric ionizing radiation so refined policies can be established regarding radiation exposure limits. 


\section{References}

Badhwar, G. D., and P. M. O’Neill, Galactic cosmic radiation model and its applications, Adv. Space Res., 17, 7-17, 1996.

Badhwar, G. D., and P. M. O’Neill, Long term modulation of galactic cosmic radiation and its model for space exploration, Adv. Space Res., 14, 749-757, 1994.

Badhwar, G. D., and P. M. O’Neill, Time lag of twenty-two year solar modulation, Proc. $23^{\text {rd }}$ Int'l Cosmic Ray Conf. (Calgary), 3, 535-539, 1993.

Badhwar, G. D., and P. M. O’Neill, An improved model of galactic cosmic radiation for space exploration missions, Nuclear Tracks Radiat. Meas., 20, 403-410, 1992.

Badhwar, G. D., and P. M. O’Neill, An improved model of galactic cosmic radiation for space exploration missions, Proc. $22^{\text {nd }}$ Int'l Cosmic Ray Conf. (Dublin), OG-5.2-13, 643-646, 1991.

Band, P. R., J. J. Spinelli, V. T. Y. Ng, J. Moody, and R. P. Gallagher, Mortality and cancer incidence in a cohort of commercial airline pilots, Aviat. Space Environ. Med., 61, 299-302, 1990.

Barish, R. J., In-flight radiation exposure during pregnancy, Obstet. Gynecol., 103, 13261330, 2004.

Barish, R. J., Health physics concerns in commercial aviation, Health Phys., 59, 199-204, 1990.

Barton, C. E., International Geomagnetic Reference Field (IGRF): the seventh generation, J. Geomag. Geoelectr., 49, 123-148, 1997.

Blattnig, S. R., G. De Angelis, F. F. Badavi, R. B. Norman, and J. W. Norbury, Preliminary analysis of pion and muon radiations on Mars, submitted to Advances in Space Research, 2005.

Blattnig, S. R., J. W. Norbury, R. B. Norman, J. W. Wilson, R. C. Singleterry, R. K. Tripathi, MESTRN: A Deterministic Meson-Muon Transport Code for Space Radiations, NASA/TP-2004-212995, 2004.

Bramlitt, E. T., Commercial aviation crewmember radiation doses, Health Phys., 49, 945948, 1985.

Clowdsley, M. S., et al., Shuttle Induced Neutron Environment: Computational Requirements and Validation, International Conference on Environment Systems, SAE 2002-01-2460, 2002.

Clowdsley, M. S., et al., A comparison of the multigroup and collocation methods for solving the low-energy neutron Boltzmann equation, Can. J. Phys., 78, 45-56, 2000.

Clem, J. M., G. De Angelis, P. Goldhagan, and J. W. Wilson, Preliminary validation of computational procedures for a new atmospheric ionizing radiation (AIR) model, Adv. Space Res., 32(1), 27-33, 2003.

Clem, J., D. P. Clements, J. Esposito, P. Evenson, D. Huber, J. L’Heureux, P. Meyer, and C. Constantin, Solar modulation of cosmic electrons, Astrophys. J., 464, 507, 1996.

De Angelis, G., J. M. Clem, P. E. Goldhagen, and J. W. Wilson, A new dynamical ionizing radiation (AIR) model for epidemiological studies, Adv. Space Res., 32(1), 17-26, 2003.

Engelmann, J. J., P. Ferrando, A. Soutoul, P. Goret, E. Juliusson, L. Koch-Miramond, N. Lund, P. Masse, B. Peters, N. Petrou, and I. L. Rasmussen, Charge composition and 
energy spectra of cosmic-ray nuclei for elements from Be to Ni. Results from HEAO-3-C2, Astron. Astrophys., 233, 96-111, 1990.

Foelsche, T., R. B. Mendell, J. W. Wilson, and R. R. Adams, Measured and calculated neutron spectra and dose equivalent rates at high altitudes: Relevence to SST operations and space research, NASA TN D-7715, 1974.

Foelsche, T., Radiation Exposure in Supersonic Transports, NASA TN D-1383, 1961.

Foelsche, T., and E. H. Graul, Radiation exposure in supersonic transports, Atompraxis, 8, 365-380, 1962.

Friedberg, W., Solar Radiation Alert Systems, Airline Space Weather Workshop, National Oceanic and Atmospheric Administration, Boulder, Colorado, February, 2004.

Friedberg, W., D. N. Faulkner, L. Snyder, E. B. Darden, Jr., and K. O’Brien, Galactic cosmic radiation exposure and associated health risk for air carrier crewmembers, Aviat. Space Environ. Med., 60, 1104-1108, 1989.

Gaisser, T., Cosmic Rays and Particle Physics, Cambridge University Press, 1990.

Goldhagan, P., M. Reginatto, T. Kniss, J. W. Wilson, R. C. Singleterry, I. W. Jones, and W. Van Steveninck, Measurement of the energy spectrum of cosmic-ray induced neutrons aboeard an ER-2 high-altitude airplane, Nucl. Instr. and Meth. A, 476, 4251, 2002.

Grajewski, B., E. A. Whelan, M. A. Waters, J. S. Kesner, and T. M. Schnorr, Overview of the proposed NIOSH-FAA study of reproductive disorders in femal flight attendants, $42^{\text {nd }}$ Annual Meeting of the Radiation Research Society, Nashville, TN, 1994.

Heinrich, W., S. Roesler, and H. Schraube, Physics of cosmic radiation fields, Radiat. Prot. Dosim., 86, 253-258, 1999.

Hudson, M. K., B. T. Kress, J. E. Mazur, K. L. Perry, and P. L. Slocum, 3D modeling of shock-induced trapping of solar energetic particles in the Earth's magnetosphere, $J$. Atmos. Solar-Terr. Phys., 66, 1389, doi:10.1016/j.jastp.2004.04.024, 2004.

International Commission on Radaition Units and Measurements. The quality factor in radiation protection. Bethesda, MD: International Commission on Radiation Units and Measurements; ICRU Report 40, 1986.

International Commission on Radiological Protection. 1990 recommendations of the International Commission for Radiological Protection. New York: Elsevier Science; ICRP Publication 60; Annals of the ICRP21, 1991.

Jiang, T. N., B. I. Lord, and J. H. Hendry, Alpha particles are extremely damaging to developing hemopoiesis compared to gamma radiation, Radiat. Res., 137, 380-384, 1994.

Kahler, S. W., Origin and properties of solar energetic particles in space, in Space Weather, AGU Monograph Series, vol. 125, edited by P. Song, H. J. Singer, and G. L. Siscoe, American Geophysical Union, Washington DC, 2001.

Kim, M.-H. Y., J. W. Wilson, and F. A. Cucinotta, An improved solar cycle statistical model for the projection of near future sunspot cycles, NASA TP-2004-212070, 2004.

Kress, B. T., M. K. Hudson, and P. L. Slocum, Impulsive solar energetic ion trapping in the magnetosphere during geomagnetic storms, Geophys. Res. Lett., 32, L06108, doi:10.1029/2005GL022373, 2005. 
Kress, B. T., M. K. Hudson, K. L. Perry, and P. L. Slocum, Dynamic modeling of geomagnetic cutoff for the 23-24 November 2001 solar energetic particle event, Geophys. Res. Lett., 31, L04808, doi:10.1029/2003GL018599, 2004.

Kuhn, E., F. E. Schwamb, and W. T. Payne, Solar Flare to Earth-Orbiting Vehicles, Second Symposium on Protection Against Radiations in Space, NASA SP-71, 429434, 1965.

Lambiotte, J. J., J. W. Wilson, and T. A. Filipas, PROPER-3C: A Nucleon-Pion Transport Code, NASA TM X-2158, 1971.

Lorenc, A. C., et al., The Met. Office global three-dimensional variational data assimilation scheme, Q. J. R. Meteorol. Soc., 126, 2991-3012, 2000.

Luhmann, J. G., S. C. Solomon, J. A. Linker, J. G. Lyon, Z. Mikic, D. Odstrcil, W. Wang, and M. Wiltberger., Coupled model simulation of a Sun-to-Earth space weather event, J. Atmos. Solar-Terr. Phys., 66, 1243, doi:10.1016/j.jastp.2004.04.005, 2004.

Lyon, J. G., J. A. Fedder, and C. M. Mobarry, The Lyon-Fedder, Mobarry (LFM) global MHD magnetospheric simulation code, J. Atmos. Solar-Terr. Phys., 66, 1333, doi:10.1016/j.jastp.2004.03.020, 2004.

McMeekin, R. R., Radiation exposure of air carrier crewmembers. Washington, DC: Federal Aviation Administration; FAA Advisory Circular No. 120-52, 1990.

National Academy of Sciences/National Research Council. Health effects of exposures to low levels of ionizing radiation. Washington DC: National Academy Press: Committee on the Biological Effects of Ionizing Radiation, BEIR V, 1980.

National Council on Radiation Protection and Measurements. Limitations of exposure to ionizing radiation. Bethesda, MD: National Council on Radiation Protection and Measurements; NCRP Report No. 116, 1993.

Neher, H. V., Cosmic rays at high latitudes and altitudes covering four solar maxima, $J$. Geophys. Res., 76, 1637-1851, 1971.

Neher, H. V., Cosmic-ray particles that changed from 1954 to 1958 to 1965, J. Geophys. Res., 72, 1527-1539, 1967.

Neher, H. V., and H. R. Anderson, Cosmic rays at balloon altitudes and the solar cycle, $J$. Geophys. Res., 67, 1309-1315, 1962.

Neher, H. V., Cosmic-ray knee in 1958, J. Geophys. Res., 66, 4007-4012, 1961.

Nicholas, J. S., K. Copeland, F. E. Duke, W. Friedberg, Galactic cosmic radiation exposure of pregnant aircrew members II., Federal Aviation Administration Report DOT/FAA/AM-00/33, Wahsington, DC: FAA, 2000.

Parker, E. N., The passage of energetic charged particles through interplanetary space, Planet. Space Sci., 13, 9-49, 1965.

Reitz, G., K. Schnuer, and K. Shaw, Editorial - Workshop on radiation exposure of civil aircrew, Radiat. Prot. Dosim., 48, 3, 1993.

Shea, M. A., and D. F. Smart, A world grid of calculated cosmic ray vertical cutoff rigidities for 1980.0, $18^{\text {th }}$ International Cosmic Ray Conference-Conference Papers, MG Session, Vol. 3, Tata Instr. of Fundmental Research (Colaba, Bombay), 415418, 1983.

Smart, D. F., and M. A. Shea, A comparison of the Tsyganeko model predicted and measured cutoff latitudes, Adv. Space Res., 28, 1733-1738, 2001. 
Smart D. F., M. A. Shea, and E. O. Fluckiger, Magnetospheric models and trajectory computations, Space Science Reviews, 93, 305-333, 2000.

Spence, H., D. Baker, A. Burns, T. Guild, C.-L., Huang, G. Siscoe, and R. Weigel, Center for integrated space weather modeling metrics plan and initial model validation results, J. Atmos. Solar-Terr. Phys., 66, 1499, doi:10.1016/j.jastp.2004.03.029, 2004.

Stassinopoulos, E. G., C. A. Stauffer, and G. J. Brucker, A systematic global mapping of the radiation field at aviation altitudes, Space Weather, 1(1), 1005, doi:10.1029/2003SW000011, 2003.

Stormer, C., The Polar Aurora, Oxford at the Clarendon Press, 1965.

Swinbank, R., and A. O’Neill, A stratosphere-troposphere data assimilation system, Mon. Weather Rev., 122, 686-702, 1994.

Tsyganenko, N., A model of the near magnetosphere with dawn-dusk asymmetry: 1. Mathematical structure, J. Geophys. Res., 107(A8), 1179, doi:10.1029/2001JA000219, 2002.

Tsyganenko, N., Determination of magnetospheric current system parameters and development of experimental geomagnetic field models based on data from IMP and HEOS satellite, Planet Space Sci., 37, 5-20, 1989.

United Nations Scientific Committee on the Effects of Atomic Radiation. Sources, effects, and risks of ionizing radiation. UNSCEAR 1988 Report to the General Assembly. New York: United Nations; No. E.88.IX.7, 1988.

Upton, A. C., H. B. Chase, G. L. Hekhuis, R. H. Mole, H. B. Newcombe, J. S. Robertson, H. J. Schaefer, W. S. Synder, C. Sondhaus, R. Wallace, Radiobiological ascpects of the supersonic transport, Health Phys., 12, 209-226, 1966.

Wallance, R. G., and C. A. Sondhaus, Cosmic ray exposure in subsonic air transport, Aviation Space, and Environ. Med., 74, 6494-6496, 1978.

Wang, W., T. L. Kileen, A. G. Burns, R. G. Roble, A high resolution, three-dimensional, time dependent, nested grid model of the coupled thermosphere-ionosphere, $J$. Atmos. Solar. Terr. Phys., 61, 385-397, 1999.

Weygand, J. M., and J. Raeder, Cosmic ray cutoff prediction using magnetic field from global magnetosphere MHD simulations, Annales Geophysicae, 23, 1441-1453, 2005.

Whelan, E. A., The Working Women's Health Study: The NIOSH/FAA Study of Reproductive Disorders in Female Flight Attendants, National Institute for Occupational Safety and Health, Status Reports Q2, 2002.

Wilson, J. W., C. J. Mertens, P. Goldhagan, W. Friedberg, G. De Angelis, J. M. Clem, K. Copeland, and H. B. Bidasaria, Atmospheric ionizing radiation and human exposure, NASA/TP-2005-213935, 2005.

Wilson, J. W., R. K. Tripathi, C. J. Mertens, S. R. Blattnig, M. S. Clowdsley, F. A. Cucinotta, J. Tweed, J. H. Heinbockel, S. A. Walker, and J. E. Nealy, Verification and ValidationL High Charge and Energy (HZE) Transport Codes and Future Development, NASA/TP-2005-000000, 2005b.

Wilson, J. W., J. Tweed, S. A. Walker, F. A. Cucinotta, R. K. Tripathi, S. Blattnig, and C. J. Mertens, A benchmark for laboratory exposures with $1 \mathrm{~A} \mathrm{GeV}$ iron ions, Adv. Space Res., 35, 185-193, 2004. 
Wilson, J. W., I. W. Jones, D. L. Maiden, and P. Goldhagan (Eds.), Proceedings of the workshop on Atmospheric Ionizing Radiation (AIR): Analysis, results, and lessons learned from the June 1997 ER-2 campaign, NASA CP-2003-212155, NASA Langley Research Center, Hampton, Virginia, 2003a.

Wilson, J. W., J. E. Nealy, and G. De Angelis, F. F. Badavi, C. P. Hugger, F. A. Cucinotta, and M. Y. Kim, Dynamic/Anisotropic Low Earth Orbit Environmental Models, Proc. AIAA 2003-6621, 23-25 September, Long Beach, California, 2003b.

Wilson, J. W., Overview of radiation environments and human exposures, Heath Phys., 79(5), 2000.

Wilson, J. W., Shielding Strategies for Human Space Exploration, NASA Conference Publications 3350, edited by J. W. Wilson, J. Miller, A. Konradi, and F. A. Cucinotta, 1997.

Wilson, J. W., L. W. Townsend, W. Schimmerling, G. S. Khandelwal, F. Khan, J. E. Nealy, F. A. Cucinotta, L. C. Simonsen, J. L. Shinn, and J. W. Norbury, Transport Methods and Interactions for Space Radiations, NASA RP-1257, 1991.

Wilson, J. W., and L. W. Townsend, Radiation safety in commercial air traffic: A need for further study, Health Phys., 55, 1001-1003, 1988.

Wilson, J. W., L. W. Townsend, and B. B. Badavi, Galactic HZE propagation through the Earth’s atmosphere, Radiat. Res., 109, 173-183, 1987.

Wilson, J. W., and F. F. Badavi, Methods of galactic heavy-ion transport, Radiat. Res., 231, 1986.

Wilson, J. W., J. J. Lambiotte, T. Foelsche, and T. A. Filippas, Dose Response Functions in the Atmosphere Due to Incident High-Energy Protons with Applications to Solar Proton Events, NASA TN D-6010, 1970.

Wiltberger, M., W. Wang, A. G. Burns, S. C. Solomon, J. G. Lyon, and C. C. Goodrich, Initial results from the coupled magnetosphere-ionosphere-thermosphere model: magnetospheric and ionospheric responses, J. Atmos. Solar-Terr. Phys., 66, 1411, doi:10.1016/j.jastp.2004.04.026, 2004. 
Table 1. Current and Projected Maximum Allowable Exposure Limits (Wilson et al 1995)

\begin{tabular}{|l|c|c|c|c|}
\hline & \multicolumn{4}{|c|}{ Maximum allowable exposure, mSv } \\
\cline { 2 - 5 } & $\begin{array}{c}\text { Present } \\
\text { United States } \\
10 \text { CFR Part 20 } \\
\text { Exposure condition }\end{array}$ & $\begin{array}{c}\text { Proposed } \\
\text { United States } \\
\text { NUREG/BR-0117 } \\
\text { (1991) }\end{array}$ & $\begin{array}{c}\text { Proposed } \\
\text { NCRP Rep. } \\
116 \\
(1993)\end{array}$ & $\begin{array}{c}\text { Proposed } \\
\text { ICRP Publ. 60 } \\
\text { (1991) }\end{array}$ \\
\hline $\begin{array}{l}\text { Occupation: } \\
\text { Annual }\end{array}$ & $\begin{array}{c}\mathrm{a}_{50} \\
\text { Lifetime }\end{array}$ & 50 & 50 & 20 \\
$\begin{array}{l}\text { Pregnancy (total) } \\
\text { Pregnancy (monthly) }\end{array}$ & 5 & 5 & $\mathrm{~b}_{10 \times \text { Age }}$ & $\mathrm{c}_{2}$ \\
\hline $\begin{array}{l}\text { Public: } \\
\text { Annual, many years } \\
\text { Annual, occasional } \\
\text { Pregnancy (total) } \\
\text { Pregnancy (monthly) }\end{array}$ & $\mathrm{d}_{1}$ & 1 & 0.5 & 1 \\
\hline
\end{tabular}

${ }^{\mathrm{a}}$ Not to exceed $30 \mathrm{mSv}$ in any quarter year.

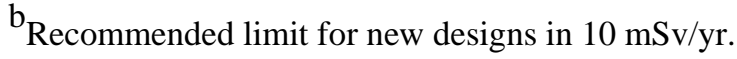

${ }^{\mathrm{C}}$ Abdomen surface for x-rays, $1 \mathrm{mSv}$ in utero.

$\mathrm{d}_{5 \mathrm{mSv}}$ allowed with prior approval of NRC. 

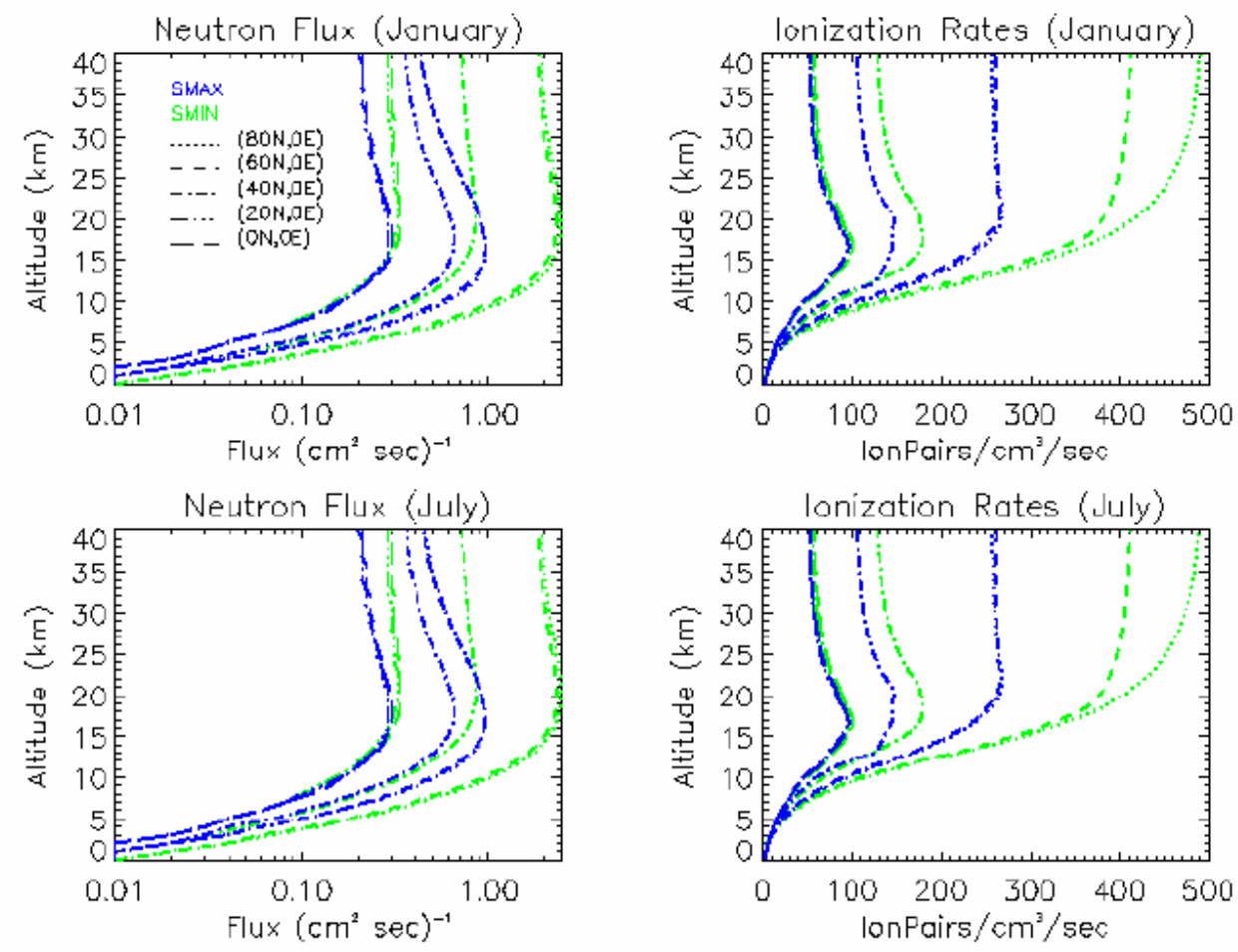

Figure 1: Neutron flux and ionization rate profiles for various latitudes. The blue lines represent solar maximum conditions. The green lines represent solar minimum conditions. The top row corresponds to January atmospheric conditions while the bottom row corresponds to July. 

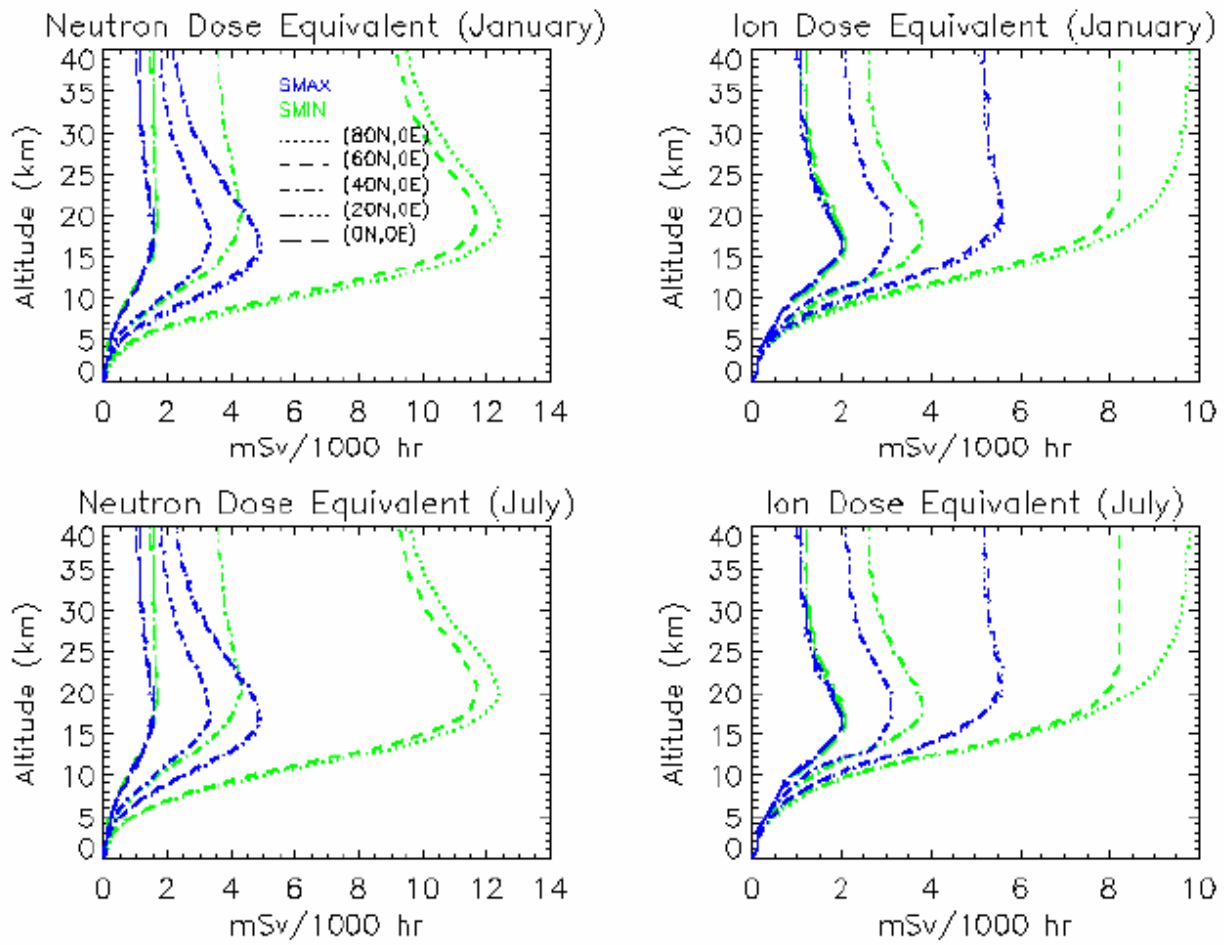

Figure 2: Neutron and ion dose-equivalent rates profiles at various latitudes. The blue lines represent solar maximum conditions. The green lines represent solar minimum conditions. The top row corresponds to January atmospheric conditions while the bottom row corresponds to July. 

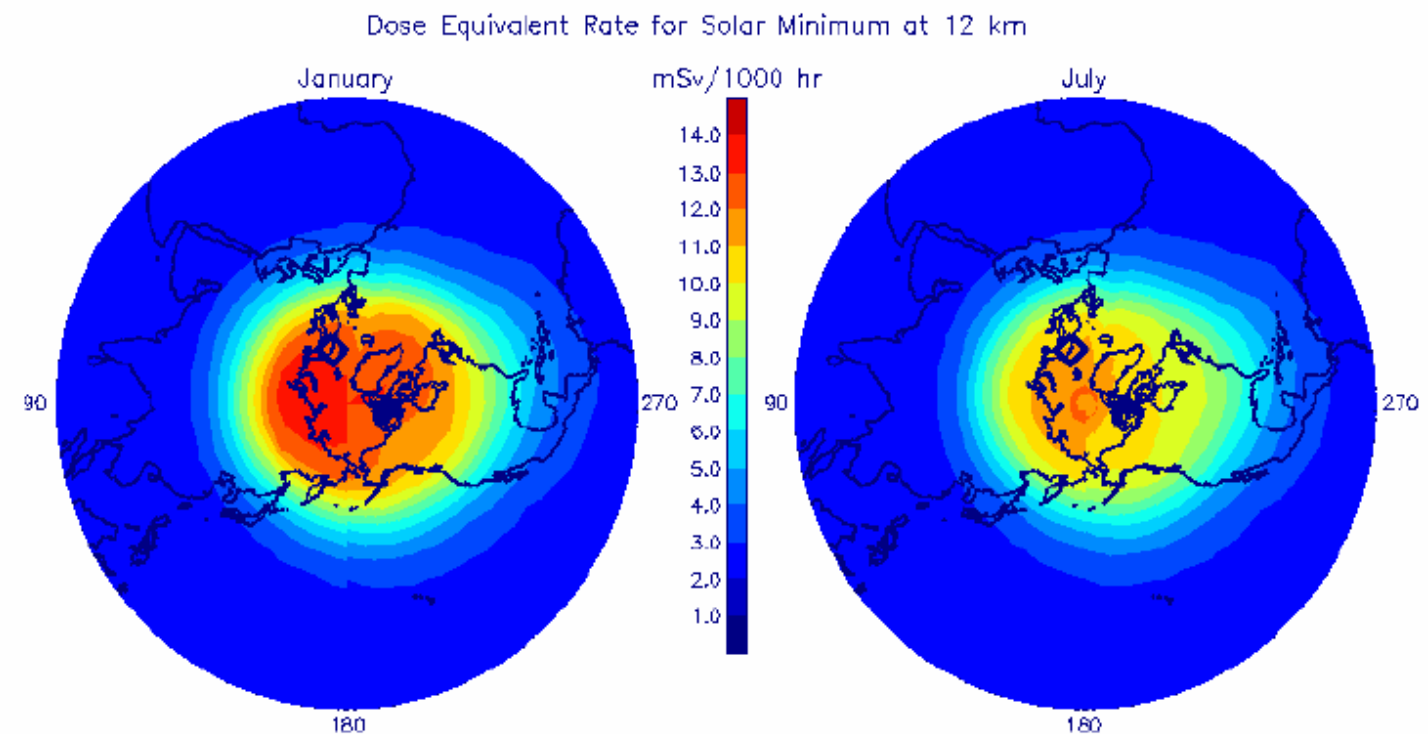

Figure 3: Northern-hemisphere dose-equivalent rates at $12 \mathrm{~km}$ for solar minimum conditions. The atmospheric condition for the left figure is January and the right figure is July. 

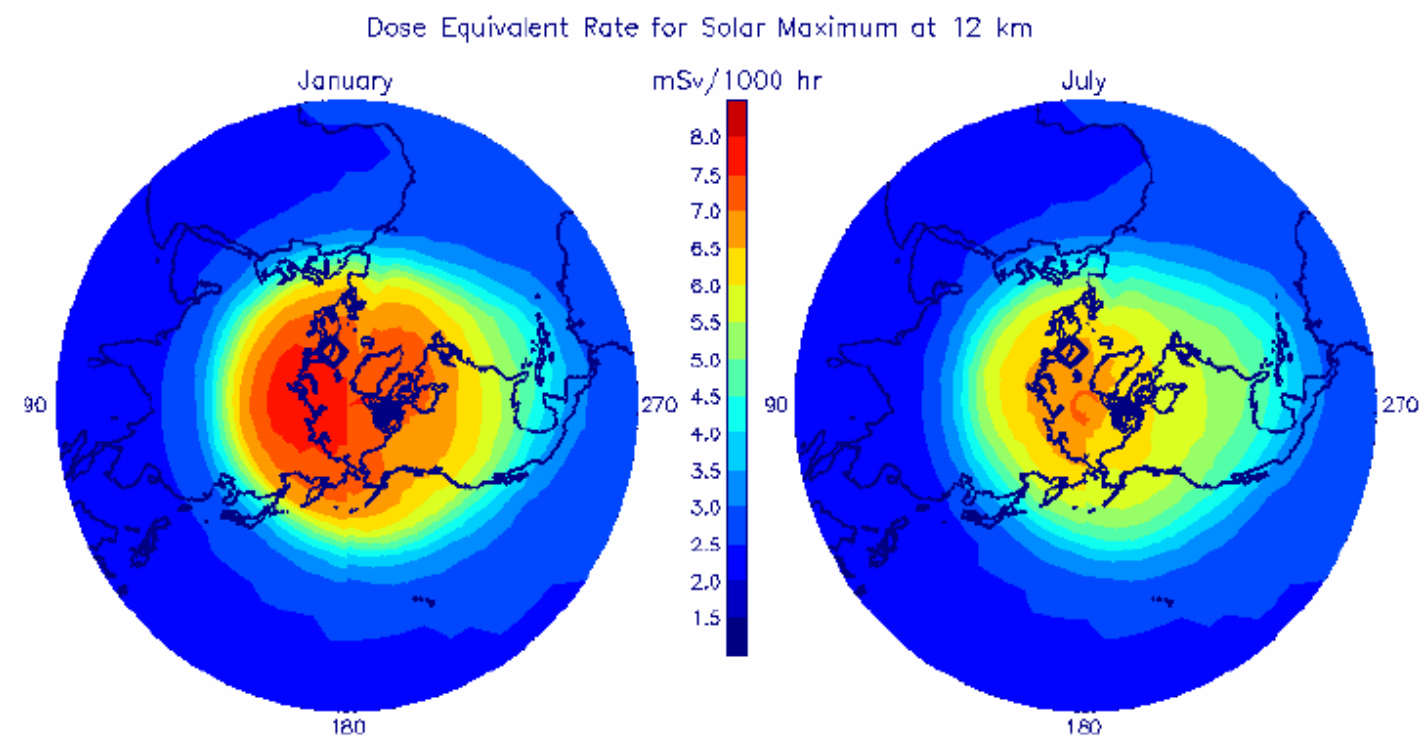

Figure 4: Northern-hemisphere dose-equivalent rates at $12 \mathrm{~km}$ for solar maximum conditions. The atmospheric condition for the left figure is January and the right figure is July. Note the difference in scale compared to Figure 3. 

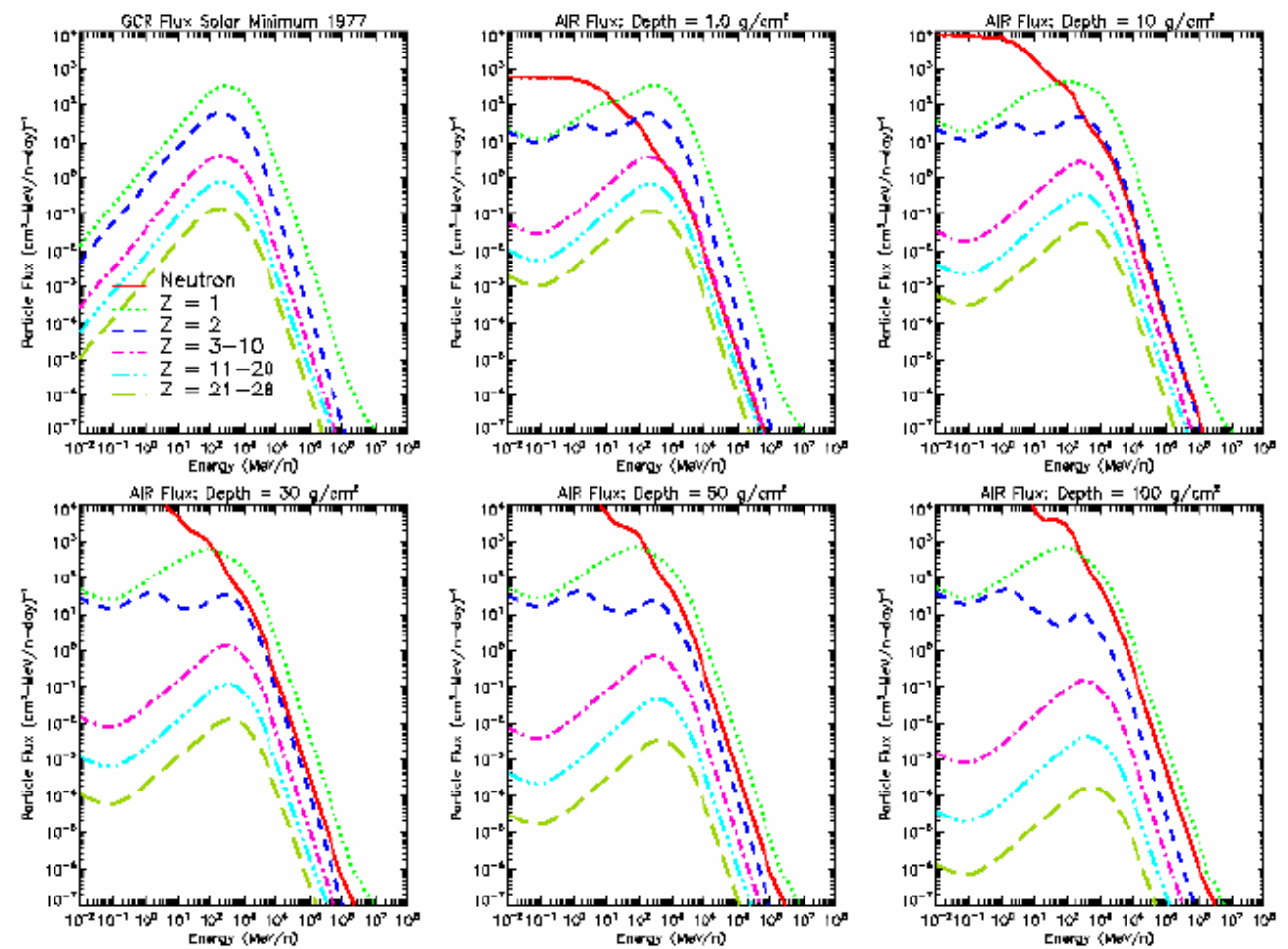

Figure 5: Differential flux computed by HZETRN at various atmospheric depths for solar minimum conditions. The figures show neutron flux and selected ion flux. 




Figure 6: Total dose-equivalent rate computed by HZETRN at various atmospheric depths for solar minimum conditions. 

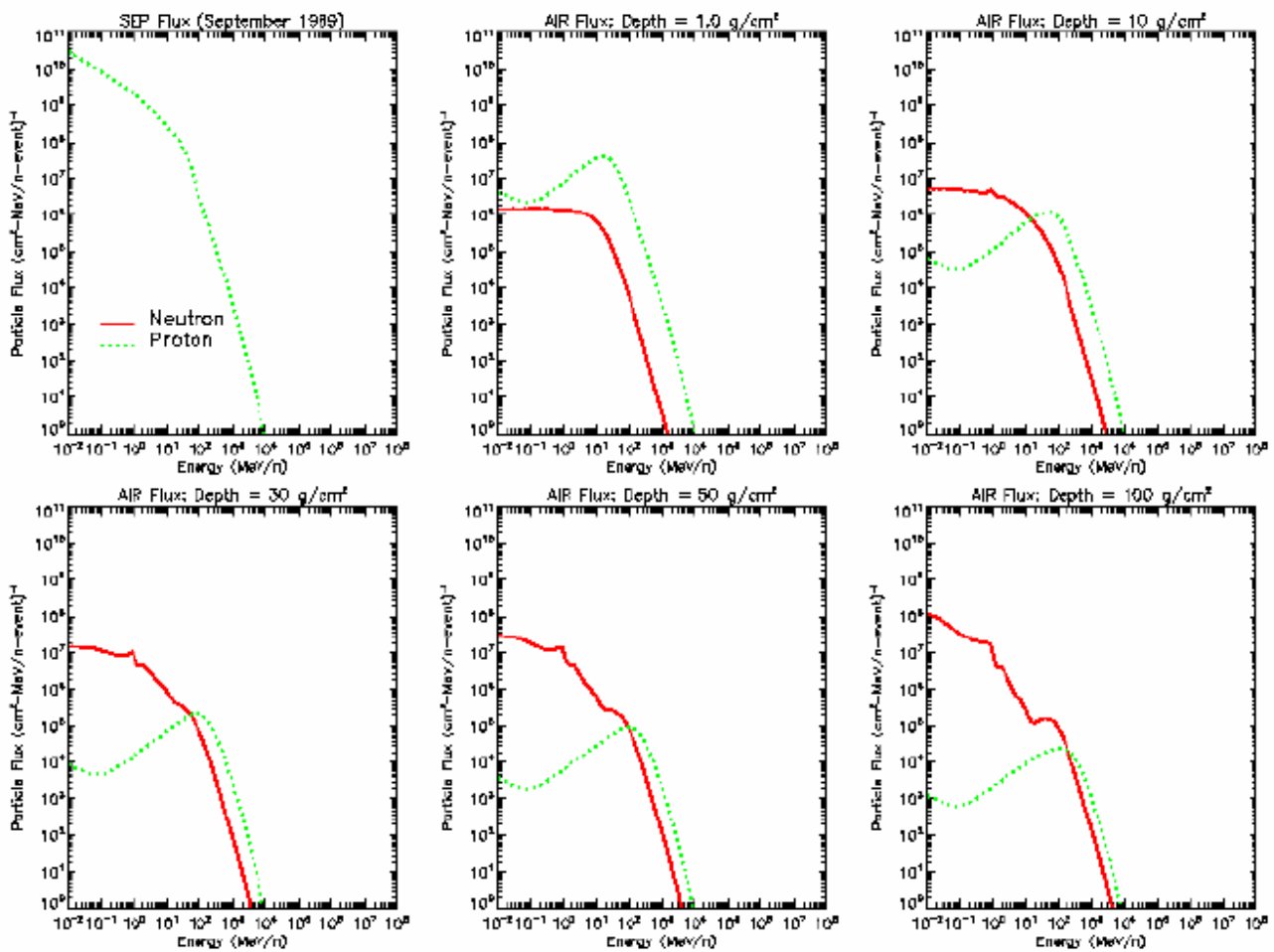

Figure 7: Event-integrated differential proton and neutron flux computed by HZETRN at various atmospheric depths for the September 1989 SEP event. 


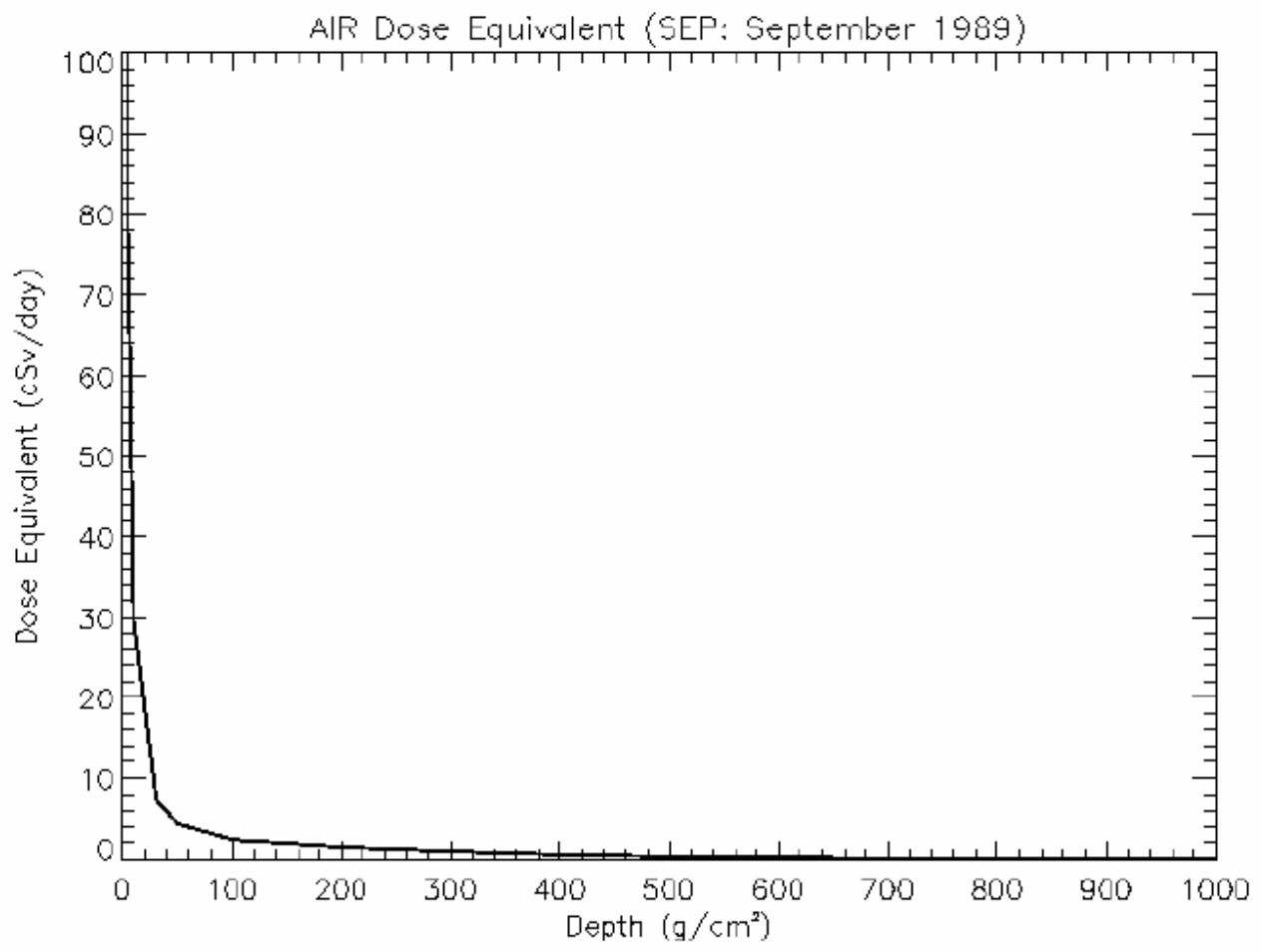

Figure 8: Event-integrated total dose-equivalent rate computed by HZETRN at various atmospheric depths for the September 1989 SEP event. 



Figure 9: GCR spectra for selected ions. The solid-red line is the local interstellar spectrum (LIS). The dashed-green line corresponds to solar minimum conditions while the dotted-blue line corresponds to solar maximum conditions. 

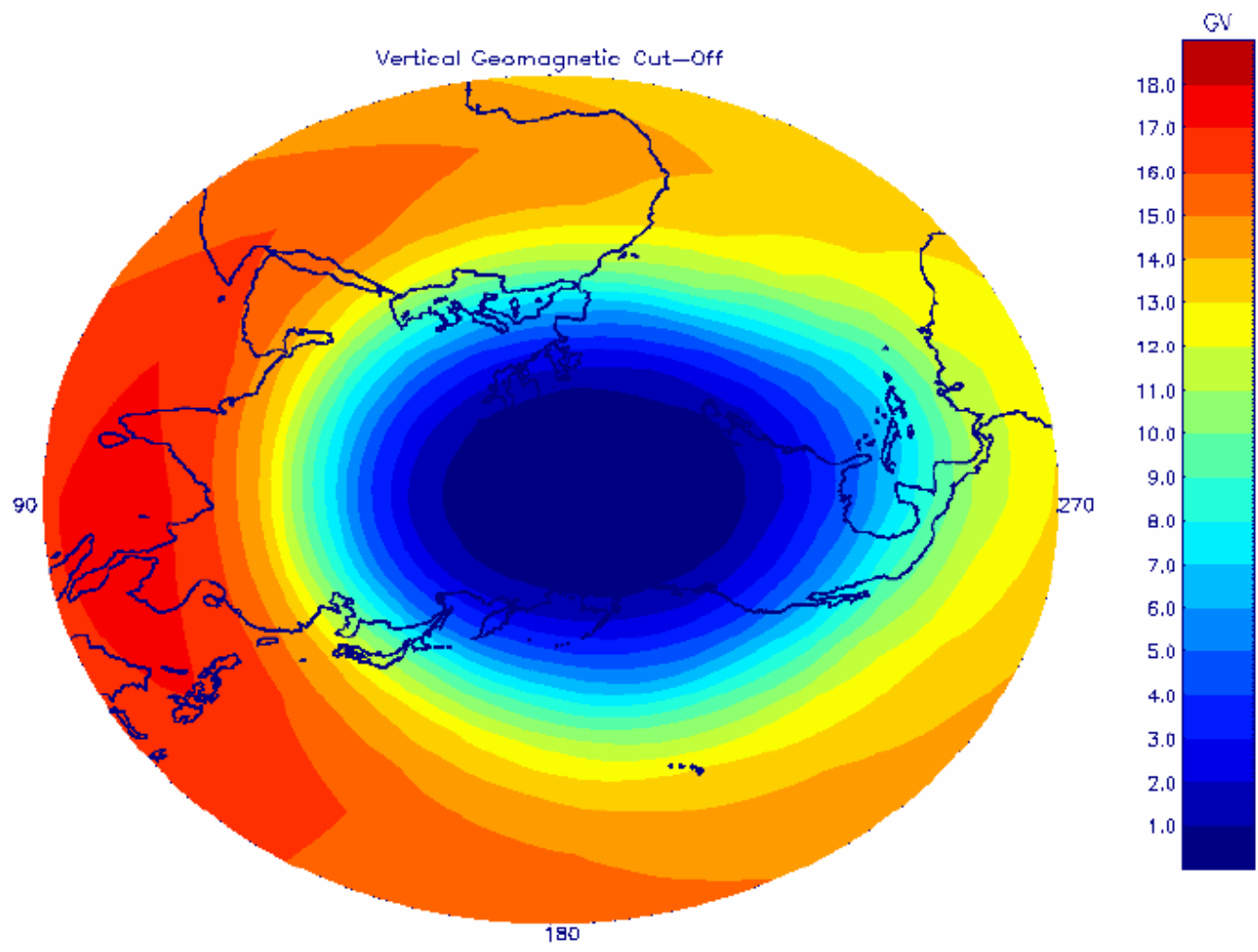

Figure 10: Northern-hemisphere vertical geomagnetic cutoff rigidities computed from particle trajectories using the IGRF model. 


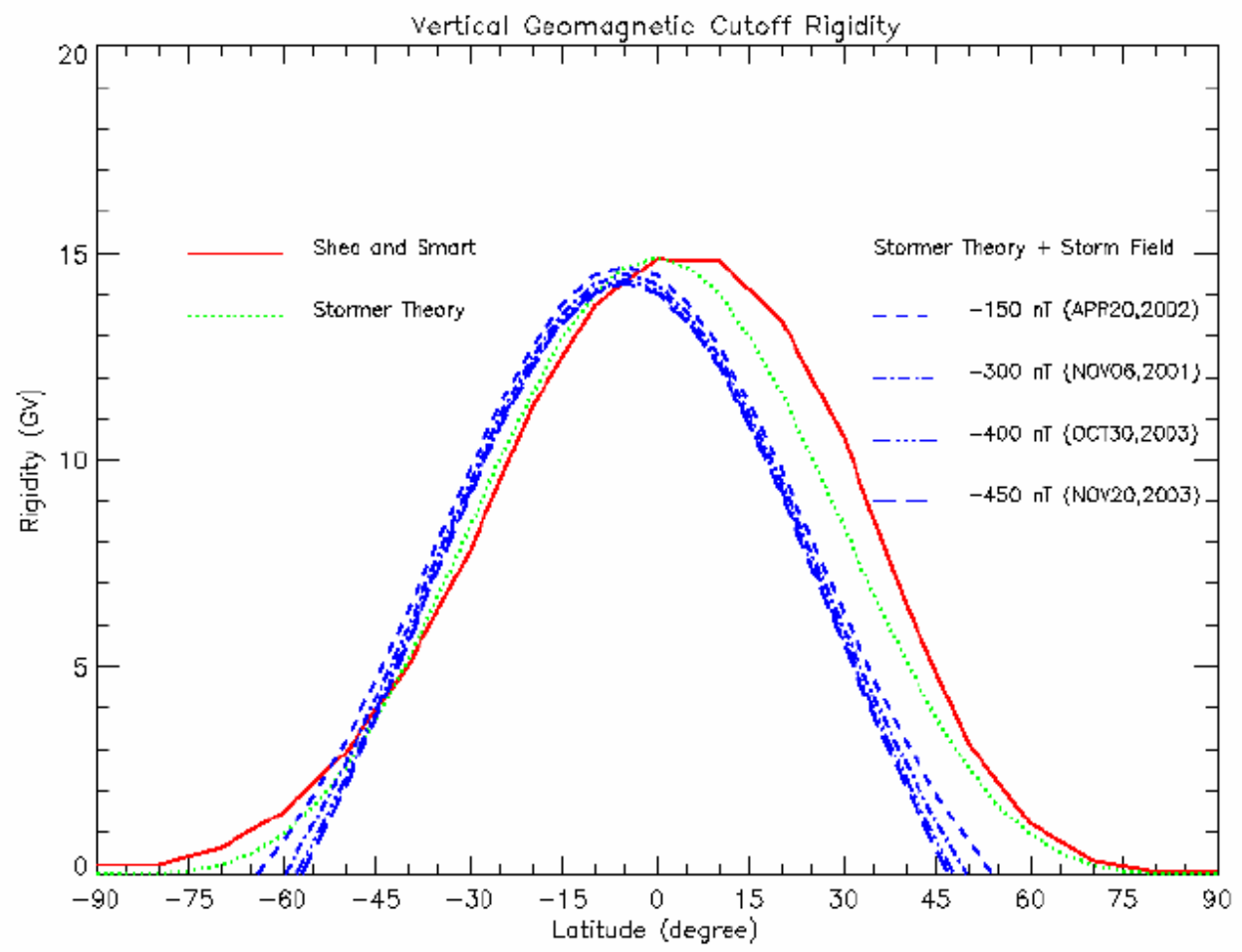

Figure 11: Zonal-averaged vertical geomagnetic cutoff rigidity. The solid-red line corresponds to the quiescent cutoff rigidities computed from particle trajectories and the IGRF model. The blue lines correspond to cutoff rigidities computed from (5) using the Dst-index to parameterize the horizontal magnetic field perturbation for recent solar-geomagnetic storms. 